\title{
Escolarização de jovens e adultos com deficiência nas pesquisas de pós-graduação no período de 2009 a 2015
}

Valéria Becher Trentin*

\section{Resumo}

A inclusão escolar requer o estreitamento nas relaçôes entre a Educação de Jovens e Adultos e a Educação Especial. $\mathrm{O}$ estreitamento nessa relação exige um movimento contínuo de reflexão, análise e discussão, materializadas por meio de pesquisas e produção do conhecimento. Neste sentido, o presente artigo tem por objetivo averiguar as pesquisas realizadas no Brasil, após a promulgação, em 2008, da Política de Educação Especial na perspectiva da Educação Inclusiva, no que tange a escolarização de alunos com deficiência na Educação de Jovens e Adultos. Para atingir o objetivo, foi realizada pesquisa bibliográfica por meio de levantamento nas bases da Coordenação de Aperfeiçoamento de Pessoal de Nível Superior (CAPES) e Banco Digital de Teses e Dissertaçôes (BDTD). Nas buscas verificaram-se as teses e dissertaçôes publicadas no período de janeiro de 2009 a setembro de 2015, utilizando os seguintes descritores: educação de jovens e adultos; deficiência; educação especial; inclusão escolar. Após levantamento realizado, foram localizadas sete dissertaçóes e três teses, que apontam em seus resultados a predominância de relatos acerca da fragilidade das estruturas na Educação de Jovens e Adultos para o atendimento educacional a pessoas com deficiência, bem como as dificuldades vivenciadas para oferecer atividades acadêmicas efetivamente enriquecedoras e eficazes para a inclusão destes jovens e adultos. Evidenciou-se ainda que a inclusão de alunos com deficiência na Educação de Jovens e Adultos é um tema novo que apresenta literatura escassa, tornando-o além de relevante nacionalmente, oportuno no contexto da construção do cenário educacional das escolas inclusivas.

Palavras-chave: Educação de Jovens e Adultos; Educação especial; Deficiência.

* Doutoranda em Educação pela Universidade do Vale do Itajaí, Itajaí, Santa Catarina, Brasil. 


\section{Youth education and adults with disabilities in research graduate 2009-2015}

\section{Abstract}

School inclusion requires the strengthening of relations between the Youth and Adult Education and Special Education. Narrowing this relationship requires a continuous movement of reflection, analysis and discussion, materialized through research and knowledge production. In this sense, this paper aims to investigate the research conducted in Brazil, following the enactment in 2008 of the Special Education Policy from the perspective of Inclusive Education, regarding the schooling of students with disabilities in the Youth and Adult Education. To achieve the goal, literature search was conducted through survey based on Higher Education Personnel Improvement Coordination (CAPES) and Digital Bank of Theses and Dissertations (BDTD). In searches there were theses and dissertations published from January 2009 to September 2015, using the following descriptors: adult education; disabilities; special education; inclusive education. After conducted survey were located 7 dissertations and 3 theses, pointing in their results the prevalence of reports about the fragility of the structures in Youth and Adult Education for educational services to people with disabilities and the difficulties experienced to offer academic activities effectively enriching and effective for the inclusion of youth and adults. It also showed that the inclusion of students with disabilities in the Youth and Adult Education is a new theme that has scarce literature, making it well as nationally relevant, timely in the context of the construction of the educational landscape of inclusive schools.

Keywords: Education for Youth and Adults; Special education; Disabilities.

\section{Introdução}

A inclusão escolar tem sido um dos principais temas de discussão no âmbito educacional. Tais discussóes promovem avanços nas pesquisas científicas na área da Educação, abarcando diferentes modalidades de atendimentos, tais como: Educação Infantil, Ensino fundamental, Educação Especial, Educação de Jovens e Adultos e Ensino Superior. No que concerne as produçôes cientificas percebe-se o quanto o pressuposto de uma inclusão escolar efetiva, que assegure o direito de igualdade com equidade para todos vem sendo abordada. O documento subsidiário à Política de Inclusão (BRASIL, 2007), demonstra ideias sobre o movimento inclusivo:

As duas últimas décadas foram marcadas pelo debate da inclusão, estabelecendo como componente fundamental a universalização do acesso à educação, o desenvolvimento de uma pedagogia centrada na criança, a ampliação da participação da família e da comunidade, a organização das escolas para a participaçáo e aprendizagem de todos os alunos e a formação de redes de apoio a inclusão. Esta postura ativa de identificação das barreiras que alguns alunos encontram no acesso à educação e também a busca dos recursos necessários para ultrapassá-los se constituiu no mo- 
vimento da inclusão e da consolidação de um novo paradigma educacional referenciado na concepção de educação inclusiva, que tem como desafio a construção de uma escola aberta às diferenças e uma sociedade que reconhece e valoriza a diversidade. (BRASIL, 2007, p. 47-48).

A inclusão escolar se apresenta como uma perspectiva na qual a matrícula do aluno com deficiência na escola não é suficiente para que esta se torne inclusiva. A inclusão escolar visa transformações que promovam a "[...] igualdade de oportunidades, respeito às necessidades individuais, qualidade no processo de ensino-aprendizagem, melhoria das condiçôes de trabalho dos professores, maior participação das famílias e da sociedade em geral, remoção das barreiras para aprendizagem e participação." (CARVALHO, 2004, p.79). Assim, entende-se que as transformaçóes nas escolas não são uma mera exigência da inclusão de pessoas com deficiência. As transformações devem ser vistas como um compromisso inadiável, que terá a inclusão escolar como consequência. Frente as transformaçóes que a inclusão escolar pressupóe, destaca-se o estreitamento entre a Educaçáo Especial e a Educaçáo Comum, para atender à diversidade presente nas salas de aulas, do ensino regular e na modalidade da Educação de Jovens e Adultos, decorrente do acesso de pessoas com deficiência, síndromes e transtornos globais do desenvolvimento.

A Educação de Jovens e Adultos, a partir da Lei de Diretrizes e Bases da Educação Nacional (LDBN 9.394/96) na Seção V, Art. 370 torna-se uma modalidade de ensino da educação básica "destinada àqueles que não tiveram acesso ou continuidade de estudos no ensino fundamental e médio na idade própria." A referida lei ainda apresenta capítulo específico em que destaca a Educação de Jovens e Adultos como modalidade de ensino a ser incorporada no conjunto das políticas de educação básica, e oferecida regularmente pelos sistemas públicos e privados de ensino. Neste sentido, compreende-se que a Educação de Jovens e Adultos (EJA), institui-se como modalidade de ensino destinada a atender as pessoas que provavelmente, e pelas mais variadas circunstâncias, não tiveram acesso ao sistema educacional em época apropriada, ou ainda que retornaram às salas na modalidade da EJA, buscando superar as dificuldades vivenciadas em seu cotidiano escolar. Na mesma direção a Política de Educação Especial na Perspectiva da Educação Inclusiva (2008) menciona as modalidades de Educação de Jovens e Adultos e a Educação Profissional, como possibilidades de ampliação de oportunidades de escolarização e formação para a inclusão no mundo do trabalho, além da efetiva participação social das pessoas com deficiências.

A inclusão escolar de alunos com deficiência na Educação de Jovens e Adultos esta ocorrendo de maneira mais acentuada nos últimos anos como consequência da ampliação do acesso ao ensino regular de maneira geral. Os dados do Censo Escolar da Educação Básica, divulgados pelo Instituto de Estudo e Pesquisas Educacionais Anísio Teixeira (INEP), por meio dos microdados da Educação Básica, indicaram que no ano de 2013 houve matricula de 3.772,670 alunos na Educação de Jovens e Adultos e, destes 51.074 público alvo da Educação Especial. Diante destes números, observa-se significativa mudança no perfil dos alunos atendidos pela modalidade da EJA, os quais não se restringem mais a pessoas que não tiveram acesso à escolarização 
em época apropriada, mas também aos que, mesmo escolarizados, não tiveram aprendizagens significativas para o desenvolvimento e participação plena nos contextos sociais. Nessa perspectiva pensar o aluno jovem e adulto com deficiência, implica refletir sobre a interface entre Educação Especial e Educação de Jovens e Adultos.

Estudos realizados sobre a escolarização das pessoas com deficiência na EJA apontam a necessidade de pesquisas que analisem a situaçáo educacional, destes alunos, pois esta enfrenta "[...] uma série de problemas pedagógicos e políticos, dificultando assim uma escolarização de qualidade para estas pessoas que não tiveram acesso ou foram excluídas do espaço educacional." (GONÇALVES; MELETTI 2011, p. 861). Embora pertinente o tema escolarizaçáo de jovens e adultos com deficiência, na EJA, apresenta literatura escassa, tornando-se urgente debates acerca da questáo, uma vez que seguindo o movimento inclusivo, a EJA se apresenta como uma possibilidade educativa para as pessoas com deficiência. A escassez na literatura pode ser comprovada por levantamento feito nas bases da Coordenação de Aperfeiçoamento de Pessoal de Nível Superior (CAPES) e Banco Digital de Teses e Dissertaçóes (BDTD), no período de 2009 à 2015. Neste sentido, cabe questionar, no entanto, como vem se configurando as pesquisas sobre o processo de escolarizaçáo de alunos com deficiência na Educaçáo de Jovens e Adultos? Procura-se, no decorrer do artigo, responder ao questionamento, à luz das pesquisas (Teses e Dissertaçôes) de Pós-Graduação em Educação e Educação Especial.

Este artigo tem por objetivo averiguar as pesquisas realizadas no Brasil, após a promulgação, em 2008, da Política de Educação Especial na perspectiva da Educação Inclusiva, no que tange a escolarização de alunos com deficiência na Educaçáo de Jovens e Adultos. Para tanto, encontra-se dividido em três seçóes principais. Na primeira, apresenta-se a metodologia empregada na busca pelas fontes e os dados referentes ao número de pesquisas desenvolvidas em Programas de Pós-Graduação em Educação e Educação Especial sobre escolarização, educação de jovens e adultos e deficiência. Na segunda seção, serão abordados e discutidos os resultados das investigaçôes realizadas pelas pesquisas examinadas e na terceira as consideraçóes finais.

\section{Metodologia}

De abordagem qualitativa, foi utilizada a pesquisa bibliográfica, que, segundo Gil (2008), é uma técnica utilizada com grande frequência em estudos exploratórios ou descritivos, casos em que o objeto de estudo proposto é pouco estudado e implica um conjunto ordenado de procedimentos de busca de soluçôes, atento ao objeto de estudo. Para o desenvolvimento deste estudo, foi utilizada como fontes de coleta de dados a Biblioteca Digital de Teses e Dissertaçôes (BDTD) e a Coordenação de Aperfeiçoamento de Pessoal de Nível Superior (CAPES). Foram realizadas buscas de teses e dissertaçóes publicadas no período de janeiro de 2009 a setembro de 2015, utilizando os seguintes descritores: educação de jovens e adultos; deficiência; educação especial; inclusão escolar. Após levantamento, foram encontradas 121 pesquisas entre teses e dissertaçôes sobre a temática Escolarização e Educaçáo de Jovens e Adultos, sendo que somente 10 tiveram como foco a deficiência e a Educaçáo de Jovens e Adultos. 
Tabela 1 - Pesquisas sobre a Temática Educação de Jovens e Adultos e Deficiência Intelectual(2009/2015).

\begin{tabular}{cccc}
\hline Ano & Dissertaçóes & Teses & Total \\
\hline 2009 & - & - & - \\
2010 & 1 & 1 & 2 \\
2011 & - & - & - \\
2012 & 3 & - & 3 \\
2013 & 1 & 1 & 2 \\
2014 & 1 & 1 & 2 \\
2015 & 1 & - & 1 \\
\hline Total & 7 & $\mathbf{3}$ & $\mathbf{1 0}$
\end{tabular}

Fonte: Biblioteca Digital de Teses e Dissertaçóes (http://bdtd.ibict.br/); Coordenação de Aperfeiçoamento de Pessoal de Nível Superior (http://www.capes.gov.br/).

Das dez pesquisas, cinco foram desenvolvidas em instituiçóes localizadas no estado de São Paulo, uma em Paraíba, duas no Paraná, e duas no Rio Grande do Sul, o que nos permitiu conhecer como a temática sobre a escolarização do aluno com deficiência na Educação de Jovens e Adultos, vem sendo pouco debatida em pesquisas no Brasil.

As pesquisas analisadas nesse artigo trazem para discussóes questóes relacionadas às trajetórias escolares de alunos com deficiência; matrículas de alunos com deficiência na Educação de Jovens e Adultos; inclusão escolar de alunos com deficiência na Educação de Jovens e Adultos e as práticas pedagógicas; a evolução ao direito a educação de jovens e adultos com deficiência e a situação educacional da pessoa jovem e adulta no campo.

Os objetivos, sujeitos de pesquisa, instrumentos para coleta de dados e principais resultados alcançados pelas pesquisas desenvolvidas por Freitas (2010), Gonçalves (2012; 2014), Souza (2012), Bins (2013), Tinós (2010), Freitas (2014), Souza (2013), Hass (2013) e Lima (2015) serão apresentados, na sequência.

\section{Escolarização de alunos com deficiência na Educação de Jovens e Adultos: resultados e discussão}

A Educação de Jovens e Adultos se encontra em processo inclusivo. O número de jovens e adultos com deficiência matriculados na EJA, segundo dados do Instituto de Estudo e Pesquisas Educacionais Anísio Teixeira (INEP), é significativo, observando-se assim mudança no perfil dos alunos atendidos pela modalidade de ensino. A partir da promulgação da Política de Educação Especial na Perspectiva da Educação Inclusiva (2008), os jovens e adultos com deficiência que, mesmo escolarizados, não tiveram aprendizagens significativas para o desenvolvimento e participação plena nos contextos sociais, passam a ocupar os bancos escolares, mudando o perfil da clientela da Educação de Jovens e Adultos. Frente a esse contexto, o que as pesquisas apontam 
sobre as trajetórias escolares dos alunos com deficiência matriculados na Educação de Jovens e Adultos? Como ocorre o processo de inclusáo escolar destes alunos nesta modalidade de ensino?

Tendo como ponto de partida o questionamento acima, traz-se para a discussão as pesquisas desenvolvidas por Tinós (2010), Hass (2013), Gonçalves e Souza (2012), que discorrem sobre as matrículas e trajetórias escolares de alunos com deficiência na Educação de Jovens e Adultos.

Tinós (2010) objetivou reconhecer e desvelar as trajetórias escolares de alunos com deficiência e, assim, compreender os diferentes serviços educacionais por estes vivenciados. A autora desenvolveu sua pesquisa tendo como participantes dois jovens com deficiência intelectual matriculados na Educação de Jovens e Adultos e suas mães. Os dados foram coletados por meio de entrevistas.

Por meio das trajetórias escolares dos alunos com deficiência Tinós (2010) verificou que os serviços educacionais ofertados a estes alunos até a matrícula na Educação de Jovens e Adultos, foram: Escola Especial e Escola Regular, sendo que estes serviços não apresentaram a qualidade prevista na legislação. A autora destaca que as trajetórias escolares permitiram a compreensão de que os avanços na legislação referentes à garantia do direito à educação de qualidade, ainda estão para serem efetivados com maiores condiçôes. Tinós (2010) enfatiza que os serviços educacionais, incluindo a EJA, devem ser repensados e garantidos por políticas públicas que reconheçam o direito e as necessidades dos alunos com deficiência.

Hass (2013), ao encontro da pesquisa de Tinós (2010), buscou analisar as narrativas sobre as trajetórias de vida de jovens com deficiência. Desenvolveu sua pesquisa em quatro escolas estaduais localizadas no município de Porto Alegre que apresentaram número elevado de matrículas de alunos com deficiência na Educação de Jovens e Adultos. A partir dos pressupostos da metodologia da história oral, utilizou a entrevista aberta como instrumento de pesquisa, integrando a esta, a análise dos indicadores do Censo Escolar da Educação Básica (2010 a 2011) e a observação.

Por meio das narrativas e observação a autora verificou a necessidade de olhar o jovem e o adulto com deficiência além de suas condiçóes orgânicas, mencionando a necessidade de compreendê-los como sujeitos com possibilidades amplas de aprender. Tinós (2010) e Hass (2013) destacam há a necessidade de políticas públicas que confiram a ação sobre a oferta de Atendimento Educacional Especializado (AEE) para jovens e adultos com deficiência. Sinalizam ainda a importância de potencializar o diálogo entre as áreas da Educaçáo Especial e Educação de Jovens e Adultos, para o enfrentamento coletivo e multidisciplinar nas situaçôes desafiadoras.

Complementando os resultados apontados nas pesquisas de Tinós (2010) e Hass (2013), sobre as trajetórias escolares e os serviços educacionais, Gonçalves e Souza (2012) analisaram os microdados do Censo Escolar da Educaçáo Básica disponibilizados pelo Instituto Nacional de Estudos e Pesquisas Educacionais Anísio Teixeira (INEP), sobre as matrículas de alunos com deficiência (visual, auditiva, física e intelectual) na Educaçáo de Jovens e Adultos, a partir das etapas de ensino, dependência administrativa e faixa etária em âmbito estadual (Paraná) e nacional (Brasil). 
No que tange os resultados, Gonçalves (2012, p. 08), evidencia "um crescente número de matrículas de alunos com deficiência na EJA, apontando maior incidência de matrículas de alunos com deficiência intelectual". Em consonância ao apontado sobre as matrículas, Souza (2012, p.56) menciona que "Na EJA rural o número de matrículas de alunos com deficiência intelectual é maior que na EJA urbana." Frente aos resultados Gonçalves e Souza (2012) destacam que a EJA se tornou um espaço de inclusão das pessoas com deficiência, destacando que esta modalidade de ensino precisa estar vinculada à Educação Especial, pois em qualquer serviço educacional, a inclusão escolar deve ser elaborada e implementada, para não se tornar apenas um discurso.

No que tange a inclusão escolar de alunos com deficiência na Educação de Jovens e Adultos, destaca-se as pesquisas desenvolvidas por Souza (2013), Bins (2013), Freitas (2014) e Lima (2015).

A pesquisa desenvolvida por Lima (2015, p. 19) teve por objetivo "caracterizar o perfil do aluno da Educação de Jovens e Adultos em um município do interior paulista, entre os anos de 2011 e 2013 e descrever as práticas pedagógicas desenvolvidas com os alunos com deficiência matriculados na Educação de Jovens e Adultos do município do interior de São Paulo". A pesquisadora utilizou para a coleta de dados os seguintes instrumentos; roteiro de caracterização dos alunos, preenchido a partir dos dados coletados no sistema de cadastro; roteiro de caracterização dos professores, preenchido pelos participantes da pesquisa que foram professores da Educação de Jovens e Adultos primeiro, segmento que possuíam alunos jovens e adultos com deficiência matriculados em suas turmas e a entrevista semiestruturada realizada com os mesmos professores participantes do estudo.

Bins (2013) realizou a pesquisa em uma escola municipal de Educação de Jovens e Adultos de Porto Alegre. A autora buscou, através dos dados obtidos por meio da observação, análise de documentos e entrevistas semiestruturadas, descrever qual a realidade da educação de jovens e adultos com deficiência intelectual incluídos na EJA tendo como participantes dois jovens com deficiência intelectual matriculados na Educação de Jovens e Adultos e suas mães.

Freitas (2014), ao encontro da pesquisa de Bins (2013), buscou compreender o processo de escolarização de jovens com deficiência intelectual que frequentam a EJA. Desenvolveu sua pesquisa em uma sala de EJA de uma escola municipal situada no interior do Estado de Sáo Paulo. Participaram desta pesquisa duas jovens com deficiência intelectual, suas respectivas máes e a professora responsável pela sala da EJA. A coleta de dados ocorreu por meio de pesquisa documental, entrevista semiestruturada e observação.

Sobre os resultados, Bins (2013) ao pesquisar especificamente sobre o jovem e adulto com deficiência intelectual incluído na EJA, menciona que "estes alunos foram incluídos mais por exigências das leis do que por convicçóes e posturas realmente inclusivas." (BINS, 2013, p. 07). A autora menciona que a escola não está preparada para trabalhar com as diferenças, exigindo homogeneizaçóes tanto de alunos como de 
aprendizagens. Destaca ainda, que a EJA, mesmo sendo uma modalidade de ensino da educação básica, que possui pressupostos inclusivos, ainda não consegue trabalhar com as diferenças. Bins (2013) e Freitas (2014), ao referirem-se a inclusão de alunos com deficiência intelectual na EJA, evidenciam a necessidade de práticas pedagógicas que reafirmem as potencialidades destes alunos, sinalizando a necessidade de discussōes sobre o tema. As autoras concordam que a concretização da inclusão escolar somente será possível, com a efetivação de práticas que promovam as relaçôes sociais e culturais.

No que tange a inclusão escolar, Souza (2013, p. 12), buscou "analisar a partir do olhar das professoras, o processo de inclusão de jovens e adultos com deficiência na EJA". Participaram da pesquisa oito professoras que atuam na EJA com alunos com deficiência, em cinco instituiçóes da rede de ensino municipal de João Pessoa/ $\mathrm{PB}$. Os dados foram coletados por meio de entrevistas e observação. A autora verificou que a inclusão é percebida somente como um processo de socialização. Mediante a constatação Souza (2013) afirma que apesar da importância do espaço educacional no desenvolvimento social, é inaceitável reduzir a EJA somente à socialização. Complementando as ideias de Souza (2013), Lima (2015, p. 89) menciona que "abrir as portas da escola para o aluno com deficiência não basta e não garante a inclusão e o aprendizado, é preciso muito mais." A autora, destaca a importância da socialização frente ao processo inclusivo, desde que essa socialização esteja engajada a práticas pedagógicas que atendam a diversidade, com objetivos que venham ao encontro das necessidades de todos os alunos.

Sobre as práticas pedagógicas, Souza (2013) elucida que as professoras expressam vontade de proporcionar práticas inclusivas, no entanto enfatizam a existência de lacunas, em relação as políticas inclusivas e as formaçóes dos professores para atuarem nesta perspectiva. Lima (2015) corrobora com Souza (2013) destacando que é urgente uma reestruturação da EJA, com consideráveis alteraçôes de seus objetivos, da metodologia de trabalho, dos conteúdos abordados e do tipo de avaliaçáo a ser realizada. Os profissionais que atuam na EJA devem buscar organizar sua prática pedagógica de modo a atender a diversidade, atingindo os objetivos propostos a este público, os interesses do grupo de alunos e suas necessidades. A autora menciona que o professor sozinho não mudará a situação educacional, torna-se necessário que o poder público volte seu olhar para os profissionais que atuam nesta modalidade de ensino e dê a eles suporte, crie redes de apoio e ofereça a formaçáo continuada voltada para uma EJA inclusiva.

A pesquisa desenvolvida por Gonçalves (2014) discorre sobre a situação educacional da Educação de Jovens e Adultos, citada por Lima (2015).

Gonçalves (2014) ao analisar a situaçâo educacional da pessoa jovem e adulta no campo utilizou como procedimentos metodológicos o levantamento e análise dos indicadores sociais, censo escolar, análise histórica da Educação Especial/EJA/Campo e entrevistas semiestrutradas com pessoas que participaram do Projeto da EJA no Campo denominado PRONERA ${ }^{1}$. 
Segundo Gonçalves (2014, p. 70) “o censo demográfico demonstrou que, em média $13,5 \%$ das pessoas com deficiência visual acima de 10 anos de idade foram autodeclaradas analfabetas. $21,2 \%$ em média, das pessoas com deficiência auditiva nessa faixa etária foram autodeclaradas analfabetas. 30,2\% das pessoas com deficiência física foram autodeclaradas analfabetas e $47 \%$ das pessoas com deficiência mental foram autodeclaradas analfabetas." Mediante análise dos dados obtidos pelo censo, a autora sinaliza a falta de acesso desta população à escola em idade escolar, ou ainda, uma trajetória escolar incompleta, marcada por carências educacionais vivenciadas por esses sujeitos."

Sobre os dados do censo escolar, a autora evidencia que estes mostraram a ampliação das matrículas de alunos com deficiência na EJA no campo, com destaque para a deficiência intelectual, afirmando o resultado apresentado por Souza (2012). Os dados do censo escolar permitiram à Gonçalves (2014, p. 171) a compreensão da situação educacional da EJA nos assentamentos, concluindo que "as condiçóes das escolas são precárias, com carências de infraestrutura, que os docentes não conseguem continuar um processo de formação acadêmica devido às condiçóes de trabalho." Segundo a autora existem muitas questôes que precisam ser discutidas sobre a situação educacional no campo: as condiçóes de trabalho docente, formação docente, transporte, alimentação, acessibilidade, para que jovens e adultos com deficiência tenham garantido efetivamente o direito a educação de qualidade como previsto na legislação brasileira.

No que concerne o direito a educação, Freitas (2010), ao resgatar, sistematizar a analisar a evolução ao direito a educação de jovens e adultos com deficiência na legislação nacional, evidencia que há um longo caminho a ser percorrido para que efetivamente seja garantido o direito a uma educação de qualidade a todos os alunos, incluindo-se os jovens e adultos com deficiência. A autora acredita que seja fundamental a mudança de pelo menos cinco campos, para que se obtenha efetivamente a qualidade. Segundo a autora, estes campos são: $1^{\circ}$ no político, para que os sistemas escolares assegurem a matrícula de todo e qualquer aluno sem discriminação; $2^{\circ}$ no administrativo, garantindo as escolas o acesso aos recursos humanos, financeiros e pedagógicos que viabilizem e deem sustentação ao processo de uma escola para todos; $3^{\circ}$ no pedagógico, viabilizando formas de flexibilização do currículo de modo a atender as necessidades educacionais dos alunos, investindo na formaçáo docente para o trabalho na diversidade, bem como disponibilizando materiais e equipamentos necessários a prática pedagógica; $4^{\circ}$ no técnico-científico, investindo na formação de professores para o ensino da diversidade e $5^{\circ}$ no estrutural, por meio da garantia de acessibilidade arquitetônica de comunicação e sinalização.

Sobre o direito a educação de qualidade, Freitas (2010) evidencia que este direito é anunciado aos cidadáos, há mais de um século e a sua importância apontada nas pesquisas e leis. Se o direito a educação de qualidade fosse efetivado a realidade seria outra: o analfabetismo seria erradicado; o atendimento educacional especializado seria ofertado a todos que dele necessitassem engajado à garantia de condiçóes de acesso, permanência e conclusão da educação escolar básica. Contudo, a autora 
evidencia que a efetivação deste direito iniciará mediante comprometimento político com todos os níveis e modalidades de ensino, com oferta de uma educação que não reabasteça os estoques do analfabetismo no país e nem alimente a descriminação e a desigualdade nas escolas.

\section{Considerações finais}

As pesquisas abordadas nesse artigo trouxeram discussóes vinculadas a trajetórias escolares de alunos com deficiência; matrículas de alunos com deficiência na Educação de Jovens e Adultos; inclusão escolar de alunos com deficiência na Educação de Jovens e Adultos e as práticas pedagógicas; a evolução ao direito a educação de jovens e adultos com deficiência e a situaçáo educacional da pessoa jovem e adulta no campo. No processo de investigaçáo, tornou-se indispensável considerar as especificidades de cada pesquisa, o olhar do pesquisador perante a realidade estudada, o modo como tratou os dados coletados com vistas a atingir os objetivos propostos e, para, além disso, os saberes, perspectivas e anseios dos sujeitos envolvidos na pesquisa.

O levantamento realizado nas bases da Coordenação de Aperfeiçoamento de Pessoal de Nível Superior (CAPES) e Banco Digital de Teses e Dissertaçóes (BDTD) apontou que o crescimento no número de matrículas de alunos com deficiência na EJA, vem despertando o interesse dos pesquisadores. As teses e dissertaçóes encontradas sobre a temática escolarização de jovens e adultos com deficiência permitiram compreender que muitos dos jovens e adultos que chegam às turmas de EJA são alunos que trazem em sua trajetória, histórico de vivências educacionais em instituiçóes especializadas no atendimento de pessoas com deficiência e que vivenciaram e vivenciam as dificuldades do ensino não projetado para atender as suas peculiaridades.

Sobre o processo de ensino na Educação de Jovens e Adultos, as pesquisas discorreram sobre a necessidade de disponibilizar aos professores da Educaçáo de Jovens e Adultos, saberes e recursos pedagógicos necessários ao atendimento das especificidades dos alunos, assegurando aos professores estruturas de apoio para a realizaçáo de práticas pedagógicas compatíveis com as necessidades desses. Frente à especificidade da educação de pessoas com deficiências nas turmas de Educação de Jovens e Adultos é relevante que aprofundemos as reflexóes e debates acerca do trabalho pedagógico a ser realizado considerando os mecanismos de articulação dos saberes a serem oportunizados aos indivíduos, no sentido de viabilizar sua inserção na vida social e no mundo do trabalho.

Mediante discussóes realizadas nas pesquisas, observaram-se lacunas, pois não houve abordagens que contemplassem os mecanismos através dos quais se dá a aquisição de conhecimentos por parte de jovens e adultos com deficiência, bem como quanto aos mecanismos de articulação entre os saberes construídos no campo da Educação Especial e da Educação de Jovens e Adultos, de forma a que possamos construir sistemas educacionais eficazes ao atendimento dos interesses e necessidades desses alunos.

Nas pesquisas, constatou-se a predominância de relatos acerca da fragilidade das estruturas na Educação de Jovens e Adultos para o atendimento educacional a 
pessoas com deficiência, bem como as dificuldades vivenciadas para oferecer atividades acadêmicas efetivamente enriquecedoras e eficazes para a inclusáo destes jovens e adultos. Evidenciou-se ainda que a inclusão de alunos com deficiência na Educação de Jovens e Adultos é um tema novo que apresenta literatura escassa, tornando-o além de relevante nacionalmente, oportuno no contexto da construção do cenário educacional das escolas inclusivas, bem como importante para professores, pesquisadores da área, agentes de políticas públicas e a sociedade como um todo.

\section{Referências}

BINS,G. L. K. Adultos com deficiência intelectual incluídos na Educaçáo de Jovens e Adultos: apontamentos necessários sobre adultez, inclusão e aprendizagem. 2013. Tese (Doutorado em Educação), Pontifícia Universidade Católica do Rio Grande do Sul. Porto Alegre/RS.

BRASIL. Lei de Diretrizes e Bases da Educaçáo Nacional. Lei n. 9.394, de 20 de dezembro de 1996. D.O.U. de dezembro de 1996. Florianópolis: Sindicato das Escolas Particulares de Santa Catarina, 1996.

Documento subsidiário à política de inclusão. Ministério da Educação. Secretaria de Educação Especial, Brasília - 2007, p. 47-48.

Política nacional de educaçáo especial na perspectiva da educaçáo inclusiva. Documento elaborado pelo Grupo de Trabalho nomeado pela Portaria Ministerial n. 555, de 5 de junho de 2007, prorrogada pela Portaria n. 948, de 09 de outubro de 2008. Brasília, 2008.

PRONERA - Programa Nacional de Educação na Reforma Agrária - é uma política pública de educação envolvendo trabalhadores(as) das áreas de Reforma Agrária. Disponível em: <www.incra.gov.br/sites/.../ programa_nac_educacao_reforma_agrária>. Acesso em: set. 2015.

CARVALHO, R. E. Educaçáo inclusiva com os pingos nos is. Porto Alegre: Mediação, 2004.

FREITAS, R. P. A. A educaçáo escolar de jovens e adultos com deficiência: direito conquistado à luta pela efetivaçấo. 2010. Dissertação ( Mestrado em Educaçăo), Universidade de São Paulo. São Paulo.

FREITAS, S. A. M. Estudantes com deficiência intelectual na educaçáo de jovens e adultos: interfaces do processo de escolarização. 2014. Dissertação ( Mestrado em Educação Especial), Universidade Federal de São Carlos. São Carlos. São Paulo.

GIL, A. C. Como elaborar projetos de pesquisa. 4a edição. São Paulo. Atlas, 2008.

GONÇALVES, L. G. G. T. Escolarizaçáo de alunos com deficiência na educaçáo de jovens e adultos: uma análise dos indicadores educacionais brasileiros. 2012. Dissertação (Mestrado em Educação), Universidade Estadual de Londrina. Londrina, Paraná.

Alunos com deficiência na educaçáo de jovens e adultos em assentamentos paulistas: experiências do PRONERA. 2014. Tese (Doutorado em Educaçáo), Universidade Federal de São Carlos. São Carlos, São Paulo.

GONÇALVES, L. G. G. T; MELETTI, S. M. Matriculas de alunos com deficiência intelectual na Educaçáo de Jovens e Adultos: Uma analise dos indicadores educacionais brasileiros e do Paraná. Evento da associação brasileira de pesquisadores em educação especial. 2011. Londrina. UEL. PR.

HASS, C. Narrativas e percursos escolares de jovens e adultos com deficiência: "isso me lembra uma história!”. 2013. Dissertaçáo (Mestrado em Educação), Universidade Federal do Rio Grande do Sul. Porto Alegre, Rio Grande do Sul.

INSTITUTO Nacional De Estudos E Pesquisas Educacionais Anísio Teixiera. Resumo do Censo Escolar. 2013. Disponível em: http//portal.inep.gov.br/básica-levantamentos-microdados. Acesso em: 23 maio 2015.

SOUZA, C. R. S. A Educaçáo no campo e a escolarizaçáo de pessoas com deficiência: uma análise dos indicadores sociais no Paraná. 2012. Dissertação (Mestrado em Educaçáo), Universidade Estadual de Londrina. Paraná.

SOUZA, M .C. S. A educaçáo de jovens e adultos na perspectiva da inclusão: o olhar das professoras. 2013. Dissertação (Mestrado em Educação), Universidade Federal da Paraíba. Paraíba. 
Valéria Becher Trentin

TINÓS, S. M. L. Caminhos de alunos com deficiências à educaçáo de jovens e adultos: conhecendo e compreendendo trajetórias escolares. 2010. Tese ( Doutorado em Educação Especial), Universidade Federal de São Carlos. São Carlos, São Paulo.

\section{Nota}

1 PRONERA - Programa Nacional de Educação na Reforma Agrária - é uma política pública de educaçăo envolvendo trabalhadores(as) das áreas de Reforma Agrária. BRASIL (2015).

\section{Correspondência}

Valéria Becher Trentin - APAE - Itajaí. Avenida Joca Brandão - até 381/382, Centro, CEP: 88301-440 - Itajaí, Santa Catarina - Brasil.

E-mail:valeriatret@yahoo.com.br

Recebido em 29 de setembro de 2015

Aprovado em 15 de fevereiro de 2016 